CrossMark $<$ click for updates

Cite this: Polym. Chem., 2015, 6, 7133

Received 31st July 2015, Accepted 22nd August 2015

DOI: $10.1039 /$ c5py01209k

www.rsc.org/polymers

\section{Thermoplastic polyester elastomers based on long-chain crystallizable aliphatic hard segments $\uparrow$}

\author{
Florian Stempfle, Brigitta Schemmer, Anna-Lena Oechsle and Stefan Mecking* \\ A plant-oil derived long-chain $\left(C_{23}\right) \alpha, \omega$-dicarboxylic acid and the corresponding diol provide entirely ali- \\ phatic hard segments in segmented thermoplastic polyester elastomers, with poly(tetramethylene glycol) \\ (PTMG) or carbohydrate-based poly(trimethylene glycol) (PPDO) soft segments. Physical crosslinking is \\ provided by their polyethylene-like crystallinity. Compared to materials derived from mid-chain $\left(C_{12}\right)$ \\ analogs, thermal properties are significantly enhanced, with melting points up to $96{ }^{\circ} \mathrm{C}$. These novel \\ materials feature high ductility values in combination with a good elastomeric behavior.
}

\section{Introduction}

Thermoplastic elastomers (TPEs) combine the processing and recyclable characteristics of thermoplastics with the flexibility and ductility of elastomers. ${ }^{1}$ They have found widespread applications in e.g. electronics, clothing, adhesives and automotive components. Unlike classical vulcanized rubbers they do not possess permanent chemical, but reversible physical crosslinks via crystallites. Morphologically, most TPEs are multiphase systems, with one or more types of hard phases and an elastomeric soft phase. Besides blending one possible approach to obtain such microstructures is block copolymerization. Widely used representatives of such block copolymers are styrenic ABA triblock copolymers, such as poly(styrene- $b$ butadiene- $b$-styrene) (SBS) or poly(styrene- $b$-isoprene- $b$-styrene) (SIS) from anionic polymerizations. ${ }^{2}$ Recently, analogs based partly or entirely on renewable feedstocks have also been developed. ${ }^{3}$ Additionally, AB diblock or ABA triblock copolymers can be synthesized using atom transfer radical polymerization (ATRP). ${ }^{4}$ In all these approaches polymerizations are performed in a sequential manner, adding a second monomer after one block has been grown. However, TPEs can also be generated by chain growth polymerization in a single step as illustrated by multiblock copolymers obtained via chain-shuttling ethylene/1-olefin insertion polymerizations. ${ }^{5,6}$

TPEs are also accessible via classical step-growth polymerization of difunctional monomers. For example, thermoplastic polyester elastomers consisting of amorphous poly(tetramethylene glycol) soft phases and crystalline poly(butylene terephthalate) hard segments are applied widely. ${ }^{7}$ In these TPEs

Chair of Chemical Materials Science, Department of Chemistry, University of Konstanz, 78464 Konstanz, Germany.E-mail: Stefan.mecking@uni-konstanz.de $\dagger$ Electronic supplementary information (ESI) available: Additional analytical data. See DOI: 10.1039/c5py01209k physical crosslinking is provided by crystallizable aromatic polyester hard segments. Utilization of aliphatic hard segments in such polycondensates - that is exploiting polyethylene-like crystallinity for physical cross-linking - has been prohibited by a lack of access to the required monomers. However, $\alpha, \omega$-difunctional linear long-chain compounds have recently become available from common seed oils or algae oils $^{8}$ via biotechnological ${ }^{9}$ or chemical catalytic routes such as metathesis ${ }^{10}$ or isomerizing alkoxycarbonylation. ${ }^{11}$ The long methylene sequences originating from complete incorporation of the entire fatty acid chain in these monomers impart a polyethylene-like solid state structure in all-aliphatic polyesters, polycarbonates and polyacetals. ${ }^{12}$ We now demonstrate the utility of long-chain aliphatic dicarboxylic acids and diols for the generation of all-aliphatic thermoplastic polyester elastomers.

\section{Results and discussion}

\section{Polymer composition and molecular weights}

As a diacid component erucic acid-based dimethyl-1,23-tricosanedioate was employed, together with 1,23-tricosanediol generated from the diester via catalytic hydrogenation. Dihydroxyterminated poly(tetramethylene glycol) (PTMG) and poly(trimethylene glycol) (PPDO), respectively, served as diol macromonomers for the generation of soft blocks. Note that both compounds are available industrially from 1,4-butanediol and 1,3-propanediol, respectively, derived from renewable carbohydrate feedstocks. ${ }^{13,14}$ Molecular weights of the copolymers obtained amount to $M_{\mathrm{n}} 2$ to $5 \times 10^{4} \mathrm{~g} \mathrm{~mol}^{-1}$ according to end group analysis from ${ }^{1} \mathrm{H}$ NMR spectroscopy. This is qualitatively confirmed by GPC analysis which also shows well behaved molecular weight distributions $M_{\mathrm{w}} / M_{\mathrm{n}}$ around 2 (Table 1). Note that apparent GPC molecular weight vs. polystyrene 
Table 1 Polyester-polyether copolymers based on long-chain crystallizable aliphatic hard segments

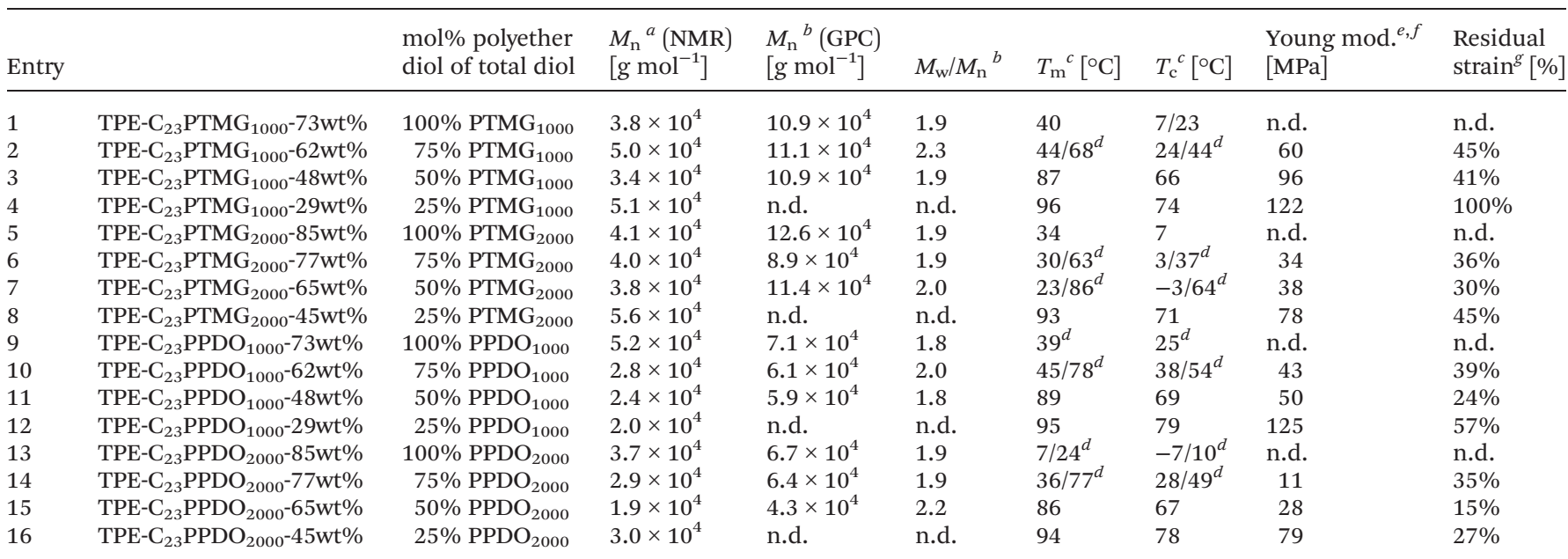

${ }^{a}$ Determined by end-group analysis from ${ }^{1} \mathrm{H}$ NMR spectroscopy. ${ }^{b}$ Determined by GPC in THF at $50{ }^{\circ} \mathrm{C}$ versus polystyrene standards. ${ }^{c}$ Determined by DSC with a heating/cooling rate of $10 \mathrm{~K} \mathrm{~min}^{-1} .{ }^{d}$ Broad melting and crystallization transitions observed. ${ }^{e}$ Tensile tests according to ISO $527 / 1-$ 2, specimen type $5 \mathrm{~A}$ prepared by injection molding. ${ }^{f}$ Crosshead speed $1 \mathrm{~mm} \mathrm{~min}^{-1} .{ }^{g}$ Determined from hysteresis experiments after 10 cycles at an elongation of $100 \%$ with a crosshead speed of $50 \mathrm{~mm} \mathrm{~min}^{-1}$.

standards typically overestimate molecular weights for polymers with hydrocarbon segments.

\section{Thermal properties}

Polycondensation of stoichiometric amounts of dimethyl-1,23trisocanedioate together with only PTMG or PPDO, respectively, yields polyester-polyether copolymers with low melting temperatures of about $40{ }^{\circ} \mathrm{C}$ for PTMG and PPDO with a number average molecular weight of about $1000 \mathrm{~g} \mathrm{~mol}^{-1}$ $\left(\mathrm{PTMG}_{1000}\right.$ and $\left.\mathrm{PPDO}_{1000}\right)$ and $34{ }^{\circ} \mathrm{C}$ or $24{ }^{\circ} \mathrm{C}$ for the corresponding polycondensate with $\mathrm{PTMG}_{2000}$ or $\mathrm{PPDO}_{2000}$ respectively (Table 1, entries 1, 5, 9 and 13. The content of the soft diol in these polymers is 73 and $85 \mathrm{wt} \%$, respectively). The thermal properties of these polymers basically reflect the polyether soft phase as the number of methylene units of the longchain dicarboxylic component alone is not sufficient to provide significant crystalline domains. In order to increase the portion of the crystalline hard phase, the polyether diol macromonomer was partially replaced by the long-chain aliphatic diol, resulting in significantly increased melt and crystallization temperatures with increasing content of 1,23tricosanediol (Table 1).

The DSC thermograms obtained for these polymers feature an additional melt peak for the crystalline hard segments, which dominates entirely at a content of the 'soft' polyetherdiol of less than $50 \mathrm{wt} \%$ (Fig. 1 and S1-S3†). This peak melting temperature of the hard segment $\left(63{ }^{\circ} \mathrm{C}\right.$ to $96{ }^{\circ} \mathrm{C}$ for PTMG copolymers and $77{ }^{\circ} \mathrm{C}$ to $95{ }^{\circ} \mathrm{C}$ for PPDO copolymers) is depressed with increasing polyether content. Such a behavior is also observed for TPEs based on crystalline poly(butylene terephthalate) hard segments and poly(tetramethylene glycol) soft phases ${ }^{15}$ and can be attributed to the larger amount of crystal imperfections due to the altered microstructure and the

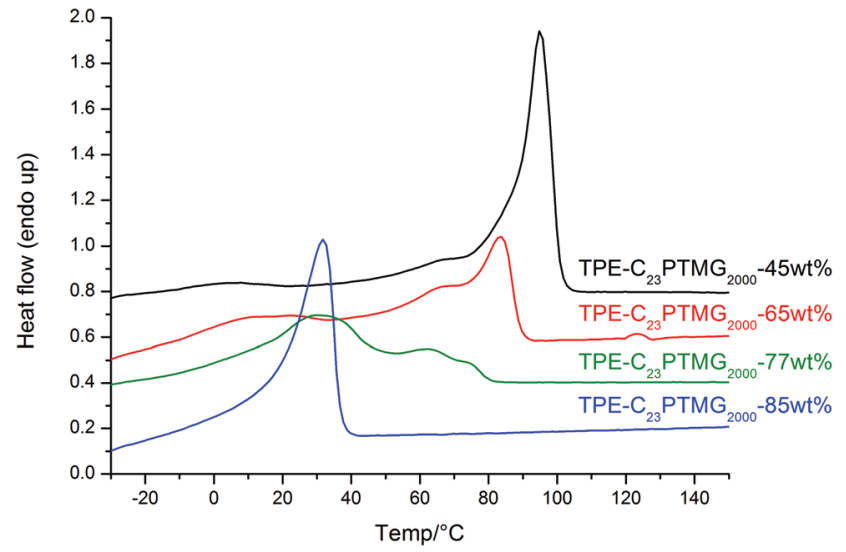

Fig. 1 DSC thermograms (second heating) of polyester-polyether copolymers based on PTMG 2000 .

consequently less favorable crystallization conditions. Note that for the PPDO containing polymers also a glass transition of the soft block was observable by DSC at $c a . T_{g}-65^{\circ} \mathrm{C}$.

\section{Mechanical properties}

Tensile tests (Table 1) were performed on specimens prepared by piston injection molding. Polymers with relatively low contents of the soft polyether phase behave like semi-rigid thermoplastics, with limited elongation at break $\left(\varepsilon_{\mathrm{b}}<200 \%\right)$ and irreversible deformation ( $c f$. entries 4 and 12 with $29 \mathrm{wt} \%$ of $\mathrm{PTMG}_{1000}$ or $\mathrm{PPDO}_{1000}$ ). However, at higher contents elastomeric behavior is observed, with satisfactory recovery and $\varepsilon_{\mathrm{b}}$ up to $>1100 \%$ (entry 10, Fig. S6†). Young moduli generally decrease with an increasing content of polyether soft segment for all polymer series, as expected (Fig. S7†). At identical 


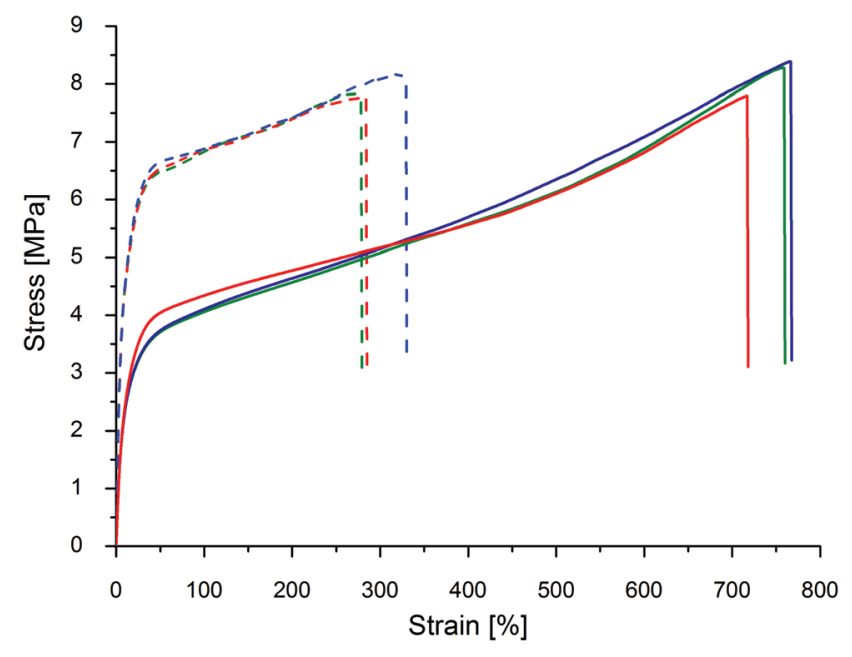

Fig. 2 Stress-strain curves of polyester-polyether copolymers TPE- $\mathrm{C}_{23} \mathrm{PTMG}_{2000}-65 w \mathrm{w} \%$ (dashed line) and TPE- $\mathrm{C}_{23} \mathrm{PPDO}_{2000}-65 \mathrm{wt} \%$ (solid line). Crosshead speed $500 \mathrm{~mm} \mathrm{~min}^{-1}$.

copolyester mass compositions and chain lengths of the polyether segments (1000 vs. $2000 \mathrm{~g} \mathrm{~mol}^{-1}$ ), PPDO-copolymers tend to have lower Young's moduli and higher elongations at break vs. their PTMG-analogs (also $c f$. Fig. 2).

In order to assess the elastic properties of these new materials cyclic hysteresis tests were performed. Test specimens were repeatedly exposed to consecutive cycles of loading and unloading to a constant strain of $100 \%$ (Table 1). Upon cyclic repetition with up to 100 cycles, after the first few cycles, where the residual deformation gradually increases, all TPEs exhibit a virtually constant level of recovery. This behavior is typical for TPEs ${ }^{1}$ and can be ascribed to the alignment of the polymer microstructure. ${ }^{16}$ After an initial change in morphology, a largely constant structure is adopted and hysteresis is observed (providing the repeated deformation is kept in the same order). For the segmented block copolymers studied here the residual strain (i.e. permanent set) after 10 cycles ranges between $30 \%$ and $100 \%$ for PTMG copolymers and between $15 \%$ and $57 \%$ for PPDO copolymers (Fig. 3). For both series, copolymers with $50 \mathrm{~mol} \%$ (of total diol) of polyether soft diol show the smallest residual strain, indicating this to be an optimum ratio of hard and soft segment. Copolymers containing polyether segments of a number average molecular weight of $2000 \mathrm{~g} \mathrm{~mol}^{-1}$ show better elastomeric behavior than the corresponding copolymers with polyether segments of $1000 \mathrm{~g} \mathrm{~mol}^{-1}$.

\section{Comparison to copolymers based on mid-chain $\left(\mathrm{C}_{12}\right)$ analogs}

In order to further assess the effect of the long hydrocarbon chain of the aliphatic hard segments, polyester-polyether copolymers based on the mid-chain aliphatic monomers dodecanedioic acid and dodecanediol with a comparable weight fraction of polyether diols were prepared (TPE- ${ }_{12} \mathrm{PTMG}_{2000^{-}}$ $62 \mathrm{wt} \%$ and $\mathrm{TPE}^{-\mathrm{C}_{12}} \mathrm{PPDO}_{2000}-62 \mathrm{wt} \%$, Table S1†). Considering

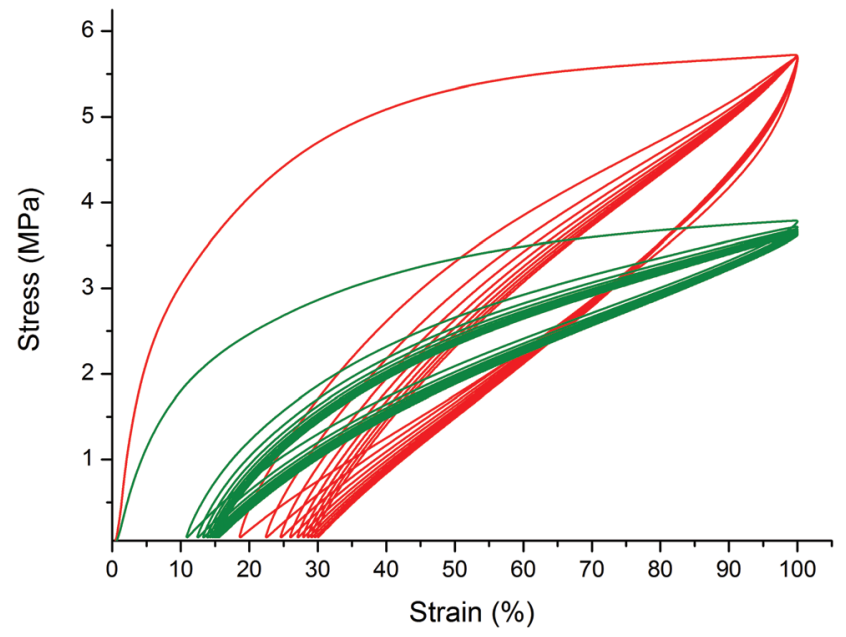

Fig. 3 Stress-strain curves from cyclic tensile tests with a constant strain of $100 \%$ for polyester-polyether copolymer TPE-C ${ }_{23} \mathrm{PTMG}_{2000}$ $65 w t \%$ (red) and TPE- $C_{23}$ PPDO $_{2000}-65 w t \%$ (green) (10 cycles) (10 cycles at a crosshead speed of $50 \mathrm{~mm} \mathrm{~min}^{-1}$ ).

their chain microstructures, the most relevant difference will be that the shortest 'hard block', i.e. an isolated diacid repeat unit, is already twice as large for the long-chain monomer based polyester $\left(\mathrm{C}_{23}\right)$ vs. its mid-chain analog $\left(\mathrm{C}_{12}\right)$. A statistical consideration of block length distributions (Fig. S14†) shows that these constitute only a relatively small portion of the aliphatic blocks in the polymer composition discussed. Overall, block length distributions are similar at the polymer composition of interest, apart from a slightly higher heterogeneity of the mid-chain polyester due to the large range of block length relevant here.

DSC analysis of TPE$^{-C_{12}} \mathrm{PTMG}_{2000}-62 \mathrm{wt} \%$ and TPE- $\mathrm{C}_{12} \mathrm{PPDO}_{2000}-62 \mathrm{wt} \%$ showed melting points of $66^{\circ} \mathrm{C}$ and $62{ }^{\circ} \mathrm{C}$, respectively, that is $20^{\circ} \mathrm{C}$ lower than for their long-chain analogs (Tables 1 and $\mathrm{S} 1 \dagger$ ). This can be attributed to a lowering of the cohesion energy by additional ester groups incorporated in the crystalline domains, and larger amount of crystal imperfections caused by the additional ester groups interrupting the crystallizable hydrocarbon chains of the hard segments and the consequent less favorable crystallization conditions.

Mechanical analysis of TPE- $\mathrm{C}_{12} \mathrm{PTMG}_{2000}-62 \mathrm{wt} \%$ and TPE- $\mathrm{C}_{12} \mathrm{PPDO}_{2000}-62 \mathrm{wt} \%$ showed that the lower chain-length of the monomers for the aliphatic hard segment does not result in dramatically different mechanical properties. TPE- ${ }_{12} \mathrm{PPDO}_{2000}-62 \mathrm{wt} \%$ exhibited a slightly higher residual strain of $22 \%$ and a significantly lower elongation at break $\left(\varepsilon_{\mathrm{b}}\right.$

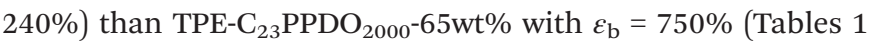
and S2; Fig. S8, S9, S12 and S13†).

\section{Experimental}

\section{Materials}

Toluene was distilled from sodium under inert gas atmosphere. Titanium(Iv) tetrabutoxide and dodecane-1,12-diol 
$(>99 \%)$ were supplied by Sigma-Aldrich and $N, N^{\prime}$-di-2naphthyl-1,4-phenylenediamine (>96\%) and dimethyl dodecanedioate $(>99 \%)$ were purchased from TCI Europe. Poly(tetramethylene glycol) with a number average molecular mass of $M_{\mathrm{n}}=1000$ purchased from Sigma-Aldrich and poly(tetramethylene glycol) with a number average molecular mass of $M_{\mathrm{n}}=2000$ kindly donated by BASF SE, as well as poly(trimethylene glycol) with a number average molecular mass of $M_{\mathrm{n}}=1000$ and 2000 respectively kindly donated by Allessa $\mathrm{GmbH}$ were all degassed prior to use. Dimethyl-1,23-tricosanedioate $^{12 d}$ and tricosane-1,23-diol ${ }^{12 d}$ were prepared from methyl erucate according to previously reported literature procedures.

\section{Characterization}

NMR spectra were recorded on a Varian Inova 400, a Bruker Avance 400 and on a Bruker Avance DRX 600 spectrometer. ${ }^{1} \mathrm{H}$ and ${ }^{13} \mathrm{C}$ chemical shifts were referenced to the solvent signals. High-temperature NMR measurements of polymers were performed in 1,1,2,2-tetrachloroethane- $d_{2}$ at $130{ }^{\circ} \mathrm{C}$.

DSC analyses were performed on a Netzsch Phoenix 204 F1 instrument with a heating and cooling rate, respectively, of $10 \mathrm{~K} \mathrm{~min}^{-1}$ in a temperature range of -50 to $160{ }^{\circ} \mathrm{C}$. Data reported are from second heating cycles.

Gel permeation chromatography (GPC) measurements were carried out on a Polymer Laboratories PL-GPC 50 with two PLgel $5 \mu \mathrm{m}$ MIXED-C columns in THF at $50{ }^{\circ} \mathrm{C}$ against polystyrene standards with refractive index detection.

Tensile testing was performed on dogbone-shaped sample bars $\left(75 \times 12.5 \times 2 \mathrm{~mm}^{3}\right.$; ISO 527-2, type 5A) which were prepared using a HAAKE Minijet II (Thermo Scientific) piston injection molder. After preconditioning the samples overnight tensile tests were performed on a Zwick Z005 and Zwick 1446 Retroline tC II instrument according to ISO 527 (crosshead

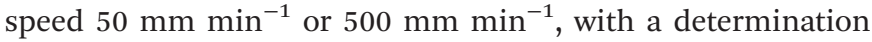
of the Young modulus at a crosshead speed of $1 \mathrm{~mm} \mathrm{~min}^{-1}$ ). The Zwick test Xpert software version 11.0 was used to collect and analyse the data. Young's modulus, yield stress, yield strain, tensile stress at break and tensile strain at break were obtained by averaging the data from several test specimens.

Cyclic hysteresis tests on dogbone-shaped sample bars $\left(75 \times 12.5 \times 2 \mathrm{~mm}^{3}\right.$; ISO 527-2, type $\left.5 \mathrm{~A}\right)$ of polyester-polyether copolymers were performed on a Zwick 1446 Retroline tC II instrument. The test specimens were repeatedly exposed to consecutive cycles of loading and unloading to a constant strain of $100 \%$ with a constant crosshead speed of $50 \mathrm{~mm} \mathrm{~min}^{-1}$. The recovery was measured by observing the residual strain after 10 cycles.

\section{General polymerization procedure}

Polycondensations were performed under inert gas atmosphere in a $100 \mathrm{~mL}$ two-necked Schlenk tube, heated with an aluminum block. The temperature was controlled by a thermocouple in the block. The polymerization mixture was mechanically stirred by a helical agitator. After weighing in the desired amount of monomers (the amount of dimethyl-1,23-tricosanedioate was set to $10 \mathrm{mmol}$ ) and $0.05 \mathrm{~mol} \%$ of $N, N^{\prime}-$ di-2- naphthyl-1,4-phenylenediamine, the mixture was degassed and heated to $120{ }^{\circ} \mathrm{C}$. Then, $0.6 \mathrm{~mL}$ of a $0.028 \mathrm{M}$ solution of $\mathrm{Ti}(\mathrm{OBu})_{4}$ in toluene was added and the temperature was increased by $10 \mathrm{~K}$ every 45 minutes. At a temperature of $180^{\circ} \mathrm{C}$ vacuum was applied to remove volatiles. The mixture was then stirred overnight at $200{ }^{\circ} \mathrm{C}$ under vacuum.

\section{Conclusions}

In summary, polycondensation of dimethyl-1,23-tricosanedioate and 1,23-tricosanediol with diol-terminated PTMG or PPDO yields polyester-polyether copolymers with molecular weights up to $M_{\mathrm{n}} 6 \times 10^{4} \mathrm{~g} \mathrm{~mol}^{-1}$. The long-chain aliphatic segments provide physical crosslinking that imparts elastomeric behavior to these thermoplastic materials. A particularly high recovery was observed at $c a$. $65 \mathrm{wt} \%$ (50 mol\% of the total diols employed) of $\mathrm{PTMG}_{2000}$ or $\mathrm{PPDO}_{2000}$ soft segments, respectively. Compared to mid-chain analogs based on $\mathrm{C}_{12}$ aliphatic monomers, melting points are significantly enhanced. This is practically relevant, as the latter materials based on traditional mid-chain monomers appear prone to a softening and loss of their elastomeric properties upon temperature variations within ambient conditions. These novel thermoplastic elastomers rely on the concept of a full incorporation of the entire length of plant oil fatty acids. Also the soft segments are derived from renewable carbohydrate feedstocks.

\section{Acknowledgements}

B.S. is grateful for a stipend provided by the State of BadenWürttemberg through the Landesgraduiertenförderungsgesetz.

\section{References}

1 (a) T. Ouhadi, S. Abdou-Sabet, H.-G. Wussow, L. M. Ryan, L. Plummer, F. E. Baumann, J. Lohmar, H. F. Vermeire and F. L. G. Malet, Thermoplastic Elastomers, in Ullmann's Encyclopedia of Industrial Chemistry, ed. W. Gerhartz and B. Elver, Wiley-VCH, Weinheim, 2014, pp. 1-41; (b) G. Holden, H. R. Kricheldorf and R. P. Quirk, Thermoplastic Elastomers, Hanser, Munich, 2004.

2 (a) G. Holden, E. T. Bishop and N. R. Legge, J. Polym. Sci., Part C: Polym. Symp., 1969, 26, 37-57; (b) M. Morton, J. E. McGrath and P. C. Juliano, J. Polym. Sci., Part C: Polym. Symp., 1969, 26, 99-115.

3 (a) C. L. Wanamaker, L. E. O'Leary, N. A. Lynd, M. A. Hillmyer and W. B. Tolman, Biomacromolecules, 2007, 8, 3634-3640; (b) M. T. Martello and M. A. Hillmyer, Macromolecules, 2011, 44, 8537-8545; (c) J. Shin, Y. Lee, W. B. Tolman and M. A. Hillmyer, Biomacromolecules, 2012, 13, 3833-3840; (d) S. Wang, S. Vajjala Kesava, E. D. Gomez and M. L. Robertson, Macromolecules, 2013, 46, 7202-7212; (e) M. A. Hillmyer and W. B. Tolman, Acc. Chem. Res., 2014, 47, 2390-2396; $(f)$ A. L. Holmberg, K. H. Reno, R. P. Wool 
and T. H. Epps, III, Soft Matter, 2014, 10, 7405-7424; $(g)$ L. Maisonneuve, T. Lebarbé, E. Grau and H. Cramail, Polym. Chem., 2013, 4, 5472-5517.

4 (a) D. P. Chatterjee and B. M. Mandal, Macromol. Symp., 2006, 240, 224-231; (b) J. Mosnáček, J. A. Yoon, A. Juhari, K. Koynov and K. Matyjaszewski, Polymer, 2009, 50, 20872094.

5 (a) D. J. Arriola, E. M. Carnahan, P. D. Hustad, R. L. Kuhlman and T. T. Wenzel, Science, 2006, 312, 714719; (b) T. Wenzel, D. Arriola, E. Carnahan, P. Hustad and R. Kuhlman, in Topics in Organometallic Chemistry, Vol. 26, ed. Z. Guan, Springer, Berlin/Heidelberg, 2009, pp. 65-104.

6 M. C. Baier, M. A. Zuideveld and S. Mecking, Angew. Chem., Int. Ed., 2014, 53, 9722-9744.

7 (a) G. K. Hoeschele and W. K. Witsiepe, Angew. Makromol. Chem., 1973, 29, 267-289; (b) R. J. Cella, J. Polym. Sci., Polym. Symp., 1973, 42, 727-740.

8 P. Roesle, F. Stempfle, S. K. Hess, J. Zimmerer, C. Río Bártulos, B. Lepetit, A. Eckert, P. G. Kroth and S. Mecking, Angew. Chem., Int. Ed., 2014, 53, 6800-6804.

9 (a) U. Schörken and P. Kempers, Eur. J. Lipid Sci. Technol., 2009, 111, 627-645; (b) S. Schaffer and T. Haas, Org. Process Res. Dev., 2014, 18, 752-766; (c) W. Lu, J. E. Ness, W. Xie, X. Zhan, J. Minshull and R. A. Gross, J. Am. Chem. Soc., 2010, 132, 15451-15455.
10 (a) M. B. Dinger and J. C. Mol, Adv. Synth. Catal., 2002, 344, 671-677; (b) H. Ngo, K. Jones and T. Foglia, J. Am. Oil Chem. Soc., 2006, 83, 629-634.

11 (a) C. Jiménez-Rodriguez, G. R. Eastham and D. J. ColeHamilton, Inorg. Chem. Commun., 2005, 8, 878-881; (b) P. Roesle, C. J. Dürr, H. M. Möller, L. Cavallo, L. Caporaso and S. Mecking, J. Am. Chem. Soc., 2012, 134, 17696-17703.

12 (a) D. Quinzler and S. Mecking, Angew. Chem., Int. Ed., 2010, 49, 4306-4308; (b) F. Stempfle, D. Quinzler, I. Heckler and S. Mecking, Macromolecules, 2011, 44, 4159-4166; (c) C. Vilela, A. J. D. Silvestre and M. A. R. Meier, Macromol. Chem. Phys., 2012, 213, 2220-2227; (d) F. Stempfle, B. S. Ritter, R. Mülhaupt and S. Mecking, Green Chem., 2014, 16, 2008-2014; (e) P. Ortmann, I. Heckler and S. Mecking, Green Chem., 2014, 16, 1816-1827.

13 Press release by BASF of March 5, 2015.

14 (a) Press release by DuPont and Tate \& Lyle of June 8, 2007. (b) M. A. Harmer, D. C. Confer, C. K. Hoffman, S. C. Jackson, A. Y. Liauw, A. R. Minter, E. R. Murphy, R. E. Spence and H. B. Sunkara, Green Chem., 2010, 12, 1410-1416.

15 K. C. Choi, E. K. Lee and S. Y. Choi, J. Ind. Eng. Chem., 2003, 9, 518-525.

16 A. Schmidt, W. S. Veeman, V. M. Litvinov and W. Gabriëlse, Macromolecules, 1998, 31, 1652-1660. 